\title{
Physicians' Knowledge, Perceptions, and Attitudes Related to Patient Confidentiality and Data Sharing
}

This article was published in the following Dove Press journal: International Journal of General Medicine

\author{
Reema Karasneh (D' \\ Abdel-Hameed Al-Mistarehi $\mathbb{D D}^{2}$ \\ Sayer Al-Azzam ${ }^{3}$ \\ Sawsan Abuhammad (D) ${ }^{4}$ \\ Suhaib M Muflih (D ${ }^{3}$ \\ Sahar Hawamdeh ${ }^{3}$ \\ Karem H Alzoubi (D) $^{3,5}$ \\ 'Department of Basic Medical Sciences, \\ Faculty of Medicine, Yarmouk University, \\ Irbid, Jordan; ${ }^{2}$ Department of Public \\ Health and Family Medicine, Faculty of \\ Medicine, Jordan University of Science \\ and Technology, Irbid, Jordan; \\ ${ }^{3}$ Department of Clinical Pharmacy, Jordan \\ University of Science and Technology, \\ Irbid, Jordan; ${ }^{4}$ Department of Maternal \\ and Child Health, Jordan University of \\ Science and Technology, Irbid, 22। I0, \\ Jordan; ${ }^{5}$ Department of Pharmacy \\ Practice and Pharmacotherapeutics, \\ College of Pharmacy, University of \\ Sharjah, Sharjah, United Arab Emirates
}

Correspondence: Reema Karasneh Department of Basic Medical Science, Faculty of Medicine, Yarmouk University, P.O. Box 566, Irbid, 21 I63, Jordan Tel +962 272 IIIIII Ext 7|4I

Fax +96227211162

Email reema.karasneh@yu.edu.jo
Background: The protection of patient confidentiality is an essential practice for the successful provision of healthcare. This study examines physicians' knowledge and attitudes related to data sharing and patient confidentiality.

Methods: This is a descriptive, questionnaire-based study. Physicians were invited via e-mail to complete the study survey. The survey comprised three sections related to knowledge, attitudes, and demographic characteristics.

Results: A total of 221 physicians, with varying levels of experience and from a range of specialty areas, completed the study survey. Ethical dilemmas were encountered annually by physicians specialized in family medicine and daily by physicians in internal medicine wards more often than those in other departments. The mean score for knowledge was 7.34 (out of 14; SD=2.92) and had a positive correlation with attitudes towards the protection of data confidentiality $\left(r^{2}=0.282\right.$, $p<0.001)$. Undergraduate courses were the main source of knowledge related to ethical issues $(167 ; 74.9 \%)$. Sex $(\mathrm{B}=-1.47, p=0.001)$, marriage $(\mathrm{B}=-1.198, p=0.021)$, and source of consultation $(\mathrm{B}=-.248, p=0.02)$ were all found to predict knowledge scores. Likewise, attitudes were predicted by experience $(\mathrm{B}=0.279, p<0.001)$, sex $(\mathrm{B}=-2.797, p=0.002)$, marriage $(\mathrm{B}=1.91, p=0.02)$, and number of ethical dilemmas faced $(\mathrm{B}=1.695, p<0.001)$.

Conclusion: Physicians from different departments were found to lack sufficient knowledge about many aspects of patient confidentiality. While some of the physicians' practices complied with the law, other practices were identified as patient confidentiality breaches.

Keywords: confidentiality, physician, knowledge, attitudes, data sharing, ethical dilemma

\section{Introduction}

Dictated in the infamous Hippocratic Oath, preserving patient confidentiality is one of the oldest cornerstones of healthcare practice. ${ }^{1,2}$ Therefore, physicians are ethically and legally obliged to maintain their patients' data privacy and protect their autonomy., However, sharing patients data with unauthorized people still frequently occur in different clinical settings and departments and, unfortunately, involve most healthcare personnel., ${ }^{5,6}$ These breaches include disclosing patient data to third parties, discussing patient information in public areas, incorrectly disposing of patient records, leaving electronic or paper health records unattended, and providing care with open doors. ${ }^{5-8}$

Concerns about sharing patients data with unauthorized people by physicians may have undesirable effects on patients' health. Breaches of confidentiality may lead to foregone healthcare, making healthcare seekers more likely to engage in dangerous behaviors or report psychological problems. ${ }^{9}$ Likewise, as these concerns may diminish 
patient's trust in their physicians, patients may hesitate to seek help, attend follow-up appointments, or even disclose essential information for the establishment of an efficient healthcare plan. $^{10,11}$

These confidentiality concerns have been acknowledged as being global concerns. Therefore, various internationally agreed recommendations and guidelines that apply to protecting the sanctity of patients' private lives during treatment had been developed that used in some countries such as United Kingdom. These regulation called Data protection Act and it was implemented in 1998 and updated on 2018. ${ }^{12-14}$ The Data Protection Act was developed to give protection and lay down rules about how data about people can be used. ${ }^{14}$ Knowledge of these codes of ethics and laws is essential for physicians to maintain ethical practices. Few studies have investigated physicians' levels of knowledge related to ethical codes ${ }^{15,17}$ and laws of data security and sharing. ${ }^{18-20}$ All professionals in healthcare, especially physicians, should be informed, aware of patients' rights. For an integrated approach to be realized in the health sector, it is obligatory that physicians persistently include the rights of patients in their actions. The most important aspect of this study is that it addresses the widely emerging trend of patient data sharing information and confidentiality among physicians in developing countries taking Jordan as an example. As a result, the authors in the study aim to examine practicing physicians' knowledge, perceptions, and attitudes related to different aspects of patient confidentiality and data sharing. Moreover, they aimed to identify the frequency of ethical dilemmas that faced in different medical departments.

\section{Methods}

\section{Study Design}

A cross-sectional survey was used to recruit responses from physicians who were employed either full-time or part-time in private or public healthcare institutions in Jordan. Physicians from all specialty areas, departments, and levels of experience were eligible to participate. This study's data were collected from May 15 to July 18, 2020, using web-based survey software (Google Forms). The validation options "Required" and "Limit to one response" were applied to minimize any cases of missing data and prevent the duplication of responses.

Physicians were recruited through e-mail and social media platforms. All participants were provided with a brief description of the study and made aware that all responses would be anonymized and treated as confidential. The participants were also informed that their participation was voluntary and that they had the right to withdraw from the study at any point.

\section{Instrument}

The survey used in the current study was developed based on an extensive review of similar literature. ${ }^{15-17}$ The following sections were included in the survey: a) sociodemographic characteristics, b) knowledge of ethical conduct, c) degree of perceived confidentiality in different clinical situations, and d) attitudes towards data sharing. The knowledge section included seven questions with the response options of "yes", "no", and "I don't know". Each correct answer was equal to two points, while each incorrect answer was equal to one point, with a maximum possible score of 14 for the knowledge section. This section was scored from 14 to 28 , as the score increase means more knowledge regarding confidentiality for patient data. The second section included seven areas about patients' data and opinion of the physician regarding the importance of keeping confidential. These situations are psychiatric diseases, chronic diseases, acute diseases, illegal drugs, food habits, sexual diseases, and therapeutic plan which the participants could respond with not important ${ }^{1}$ to important. $^{2}$ The score was ranged from 7 to 14 , greater score means more importance for keeping confidentiality toward these areas. Meanwhile, the attitudes section consisted of 14 questions scored on a 4-point Likert scale ranging from "never" to "always". This section was scored accordingly from never ${ }^{4}$ to always. ${ }^{1}$ The score in this section ranges from 14 to 56 . As the score was increased, this means more confidentiality toward patient data sharing. The survey items were reviewed by five experts in the field to identify any necessary changes and establish both face and content validity. This was followed by pilot testing the survey on 7 participants who were not included in the study sample. Cronbach's alpha values of 0.83 and 0.78 were calculated for the physicians' knowledge and attitudes, respectively, which indicated acceptable internal consistency and reliability.

\section{Ethical Considerations}

The study was conducted in compliance with the Helsinki Declaration. Ethical approval was obtained from the Institutional Review Board (IRB) at the authors' institution (IRB, Reference\# 16/121/2019). No names, addresses, or other identifying personal details were collected from the participants. 


\section{Statistical Analysis}

Data collected on Google Forms were exported to a Microsoft Excel file directly imported into IBM SPSS ${ }^{\circledR}$ version 24.0 for statistical analysis. Descriptive analysis was used to describe the sociodemographic characteristics of the participants. Pearson's correlation was conducted to determine the correlation between specialty area and frequency of ethical dilemmas and the correlation between knowledge and attitudes related to data sharing and confidentiality among the physicians. Multiple regression tests were conducted to determine the predictors of knowledge and attitudes among the physicians while controlling for demographic variables (ie, age, sex, educational level, work experience, and area of specialty).

\section{Results}

\section{Demographic Characteristics}

The results showed that the participants' average age was 33.0 $(\mathrm{SD}=10.3)$ years and $67.9 \%(\mathrm{n}=150)$ were men. Half of the participants were married (50.7\%). Detailed demographic and work characteristics of the study participants are summarized in Table 1. Ethical dilemmas were encountered weekly by $24 \%$ of the physicians, with the "colleague" was the main source for consultation in such situations. Finally, the majority of the physicians (89.1\%) showed an interest in taking a course in medical ethics.

\section{Description of Ethical Dilemmas Among Different Medical Specialities}

The results showed that physicians working in specific specialty areas faced ethical dilemmas more frequently than physicians in other areas. For example, physicians in internal medicine wards reported facing ethical dilemmas on a daily basis more often than did physicians in other departments, including surgery, family medicine, and special surgery. In comparison, physicians in family health wards reported facing ethical dilemmas on an annual basis more often than those in other areas Figure 1.

\section{Knowledge About Patient Confidentiality and Data Sharing Among the Physicians}

Table 2 illustrates the participating physicians' responses to the knowledge about data sharing and confidentiality section. The average score for knowledge about data security among the physicians was 7.34 ( $\mathrm{SD}=2.92$ ) (out of a maximum of 14 points). The questions which were most frequently answered correctly were: "Can patients' confidentiality be breached if the disease is not contagious?" $(69.7 \%, \mathrm{n}=154)$ and "Is confidentiality and access to medical records governed by law (or special recommendations and instructions)" (71.9\%, $\mathrm{n}=159$ ). Meanwhile, most of the respondents did not know the answer to the question: "Are the police allowed to access medical records freely?" $(42.1 \%, n=93)$.

Among the participants, the primary sources of medical ethics information were residency programs $(58.3 \%, \mathrm{n}=130)$, undergraduate study $(74.9 \%, \mathrm{n}=167)$, and work experience $(60.5 \%, n=134)$ (Figure 2). Other sources included lectures and seminars, personal reading, and the United States Medical Licensing Examination (USMLE).

\section{Degree of Perceived Importance of Patient Confidentiality in Different Clinical Situations}

The vast majority of the participating physicians agreed that it is "important" to maintain confidentiality when dealing with patients with psychiatric diseases $(97.3 \%, \mathrm{n}=215)$, sexual diseases $(94.1 \%, \mathrm{n}=208)$, or addiction to illegal drugs $(95.9 \%$, $\mathrm{n}=212$ ). However, maintaining confidentiality when dealing with patients with chronic diseases or when handling data related to patients' food habits was agreed to be "not important" by almost half of the participating physicians $(46.6 \%$, $47.5 \%$, respectively) (Table 3 ).

\section{Attitudes Towards Patient Confidentiality and Data Sharing Among the Physicians}

The mean score for attitudes towards data protection among the physicians was 29.3 (out of a maximum of 56 points). The majority of the physicians agreed that they collected information from patients and documented it in an entirely confidential manner $(98.2 \%, \mathrm{n}=217)$. They also agreed that they made sure to deal with sensitive information (eg, mental illnesses, sexual diseases) with extra caution $(84.1 \%, \mathrm{n}=186)$. Few physicians reported that they always or sometimes discussed their patients' conditions with colleagues in open spaces, such as reception areas and corridors $(18.5 \%, \mathrm{n}=41)$. Finally, only $17.2 \%$ of the participating physicians reported storing patient information on a personal computer (Table 4)

\section{Correlation Between Physicians' Knowledge and Attitudes Related to Data Sharing and Patient Confidentiality}

A significant correlation was identified between knowledge and attitudes related to data sharing and patient 
Table I Demographic and Work Characteristics of the Study Participants

\begin{tabular}{|c|c|c|}
\hline Variable & Category & $\mathbf{N}(\%)$ \\
\hline Age & $(M=33.0 S D=10.3)$ & \\
\hline Years of experience & $(M=7.02 S D=9.4)$ & \\
\hline \multirow[t]{2}{*}{ Sex } & Men & $150(67.9)$ \\
\hline & Woman & $71(32.1)$ \\
\hline \multirow[t]{3}{*}{ Marital status } & Single & $108(48.9)$ \\
\hline & Married & $112(50.7)$ \\
\hline & Divorced & $\mathrm{I}(0.5)$ \\
\hline \multirow[t]{8}{*}{ Specialty area } & General Surgery & $16(7.2)$ \\
\hline & Special surgery & $5(2.3)$ \\
\hline & Family Medicine & $74(33.5)$ \\
\hline & Internal Medicine & $37(16.7)$ \\
\hline & Obstetrics and gynecology & $5(2.3)$ \\
\hline & Pediatrics & $12(5.4)$ \\
\hline & Emergency Medicine & $27(12.2)$ \\
\hline & Neurology & $43(19.5)$ \\
\hline \multirow[t]{6}{*}{ Working setting } & Health center & $31(14.0)$ \\
\hline & Public hospital & $44(19.9)$ \\
\hline & Private hospital & $35(15.8)$ \\
\hline & Private clinic & $9(4.1)$ \\
\hline & Military medical services & $36(16.3)$ \\
\hline & University hospital & $66(29.9)$ \\
\hline \multirow[t]{4}{*}{ Number of patients treated/day } & Less Than 30 & $75(33.9)$ \\
\hline & $31-40$ & $77(34.8)$ \\
\hline & 40 To 60 & $24(10.9)$ \\
\hline & More Than 60 & $45(20.4)$ \\
\hline \multirow[t]{5}{*}{ Frequency of ethical dilemmas faced by physicians } & Never & $22(10.0)$ \\
\hline & Yearly & $82(37.1)$ \\
\hline & Monthly & $44(19.9)$ \\
\hline & Weekly & $53(24.0)$ \\
\hline & Daily & $20(9.0)$ \\
\hline \multirow[t]{7}{*}{ Preference in consulting on ethical dilemmas } & Colleague & $145(65.6)$ \\
\hline & Head of Department & $2(0.9)$ \\
\hline & Head of Medical Team & $20(9.0)$ \\
\hline & Head of Hospital & $2(0.9)$ \\
\hline & Ethicist & $17(7.7)$ \\
\hline & Religious Scholer & $16(7.2)$ \\
\hline & Friend & $19(8.6)$ \\
\hline \multirow[t]{2}{*}{ Further training on medical ethics is required } & Yes & $197(89.1)$ \\
\hline & No & $24(10.9)$ \\
\hline
\end{tabular}

confidentiality among the participating physicians $\left(\mathrm{r}^{2}=0.282, p<0.001\right)$. This correlation was positive, indicating that an increase in knowledge about data sharing and confidentiality is associated with better patient privacy protection by physicians.
Predictors of Physicians' Knowledge About Patient Confidentiality and Data Sharing

A multiple regression test was conducted to identify the demographic variables (ie, age, sex, educational level, work experience, and job role), which predicted 


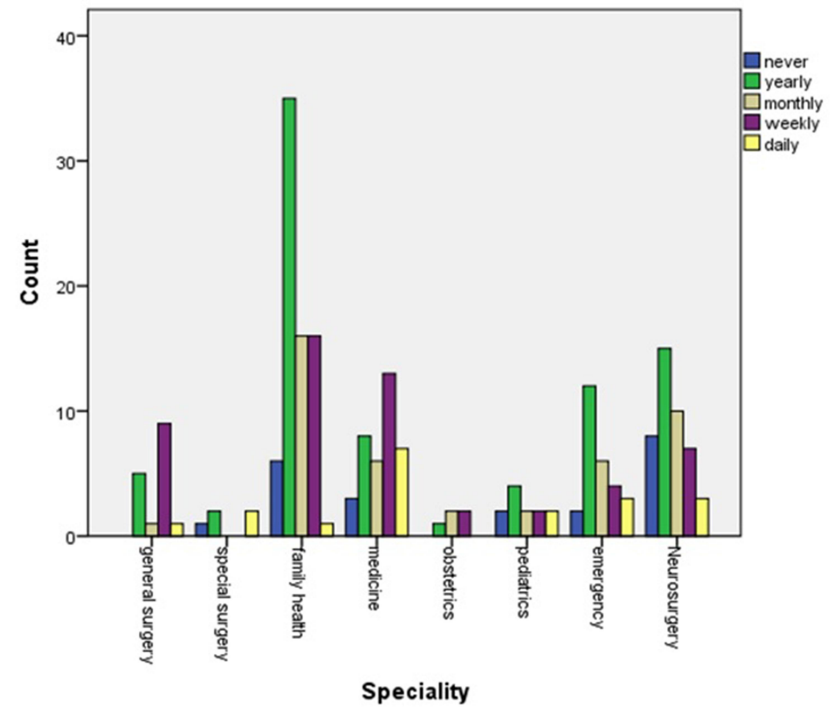

Figure I The distribution of ethical dilemmas as per physician's specialty area.

knowledge about data sharing and confidentiality among the participating physicians. The variables were found to be fit within the model $(\mathrm{F}=7.76, p=0.01)$. Table 5 summarizes the results of the multiple regression test. All of the listed factors, except for $\operatorname{sex}(\mathrm{B}=-1.47, p=0.001)$, marriage $(\mathrm{B}=-1.198, p=0.021)$, and source of consultation $(\mathrm{B}=-.248, p=0.02)$. This means higher knowledge regarding confidentiality among men compared to women. Also, the single marital status showed greater knowledge about confidentiality toward patients' data. The source of consultation was considered as a preditor which means that physicians had higher knowledge, if took the consultation from colleagues or head of departments. Other factors were found to be unassociated with knowledge about data sharing and confidentiality among the physicians $(p>0.05)$.

\section{Predictors of Physicians' Attitudes Towards Patients Confidentiality and Data Sharing}

A multiple regression test was conducted to identify the demographic variables (ie, age, sex, educational level, work experience, and job role), which predicted attitudes towards data sharing and confidentiality among the participating physicians. The variables were found to fit the model $(\mathrm{F}=3.24, p=0.001)$. Table 6 summarizes the results of the multiple regression test. Experience $(B=0.279$, $p<0.001)$, sex $(\mathrm{B}=-2.797, p=0.002)$, marriage $(\mathrm{B}=1.91$, $p=0.02)$ and the number of ethical dilemmas faced/day $(\mathrm{B}=1.695, p<0.001)$ were all found to correlate with attitudes towards data sharing and confidentiality among the participating physicians. This means more positive attitude regarding confidentiality among men compared to women. Also, the single marital status showed more positive attitude about confidentiality toward patients' data. The number of ethical dilemma faced. As the number of dilemmas were increased more positive attitude were shown toward confidentiality. Moreover, as the physician's year of

Table 2 Physicians' Responses Related to Knowledge About Data Sharing and Confidentiality

\begin{tabular}{|c|c|c|c|}
\hline & No & Yes & $\begin{array}{l}\text { I Do Not } \\
\text { Know }\end{array}$ \\
\hline & $\mathbf{N}(\%)$ & $\mathbf{N}(\%)$ & $\mathbf{N}(\%)$ \\
\hline $\begin{array}{l}\text { I. Is confidentiality and access to medical records governed by law (or unique recommendations and } \\
\text { instructions) }\end{array}$ & $23(10.4)$ & $159(71.9)$ & $39(17.6)$ \\
\hline 2. Is the non-medical information in the medical record confidential & $40(18.1)$ & $136(61.5)$ & $45(20.4)$ \\
\hline 3. Are the police allowed to access medical records freely? & III (50.2) & $17(7.7)$ & $93(42.1)$ \\
\hline $\begin{array}{l}\text { 4. Can third parties (such as insurance companies) access examination results without patient } \\
\text { consent? }\end{array}$ & $124(56.1)$ & $23(10.4)$ & $74(33.5)$ \\
\hline 5. Can patients' confidentiality be breached if he/she dies? & $104(47.1)$ & $28(12.7)$ & $89(40.3)$ \\
\hline 6. Can patients' confidentiality be breached if the disease is contagious? & $53(24.0)$ & $126(57.0)$ & $42(19.0)$ \\
\hline 7. Can patients' confidentiality be breached if the disease is not contagious? & $154(69.7)$ & $18(8.1)$ & $49(22.2)$ \\
\hline
\end{tabular}


Eesidency $\square$ Studying $\square$ Experience $\square$ Workshops $\mid$ Self-Reading $\mid$ others

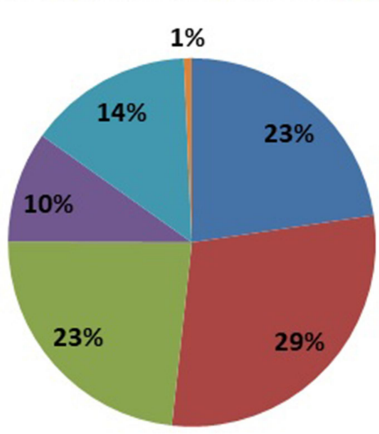

Figure 2 Source of ethics knowledge among the physicians.

experience were increased, they showed more positive attitude toward confidentiality toward patient's data.

\section{Discussion}

Patient confidentiality and data sharing practices are guided by ethical and legal principles, ${ }^{18}$ and having sufficient knowledge of these principles would help physicians resolve many of the ethical dilemmas they encounter during their clinical practice. Around two-thirds of the participants in our study reported that they were at least aware of the existence of basic governing rules related to data access and patient confidentiality. However, the participating physicians were found to have suboptimal levels of knowledge about patient confidentiality and data sharing. This suboptimal knowledge was also found to impact the physicians' attitudes and practices related to patient confidentiality and data sharing in different clinical settings. This is particularly important given the fact that many ethical dilemmas were reported to be encountered on

Table 3 Perceived Importance of Maintaining Confidentiality in Different Clinical Settings

\begin{tabular}{|l|l|l|}
\hline & Not Important & Important \\
\cline { 2 - 3 } & N (\%) & N (\%) \\
\hline I. Psychiatric diseases & $6(2.7)$ & $215(97.3)$ \\
\hline 2. Chronic diseases & $103(46.6)$ & $118(53.4)$ \\
\hline 3. Acute diseases & $75(33.9)$ & $146(66.1)$ \\
\hline 4. Illegal drugs & $9(4.1)$ & $212(95.9)$ \\
\hline 5. Food habits & $105(47.5)$ & $116(52.5)$ \\
\hline 6. Sexual diseases & $13(5.9)$ & $208(94.1)$ \\
\hline 7. Therapeutic plan & $89(40.3)$ & $132(59.7)$ \\
\hline
\end{tabular}

a weekly basis by around a quarter of the participating physicians. Further, physicians in internal medicine wards reported facing ethical dilemmas on a daily basis more often than did physicians in other departments.

Our study's physicians achieved an average score of approximately 7 out of 14 on the knowledge scale, which is considered low compared to scores reported in other studies. For example, in a recent study by Beltran et al, respondents achieved an average score of 6.8 out of 10 for knowledge. ${ }^{11}$ Insufficient knowledge of medical ethics regulations was also reported in a sample of 159 healthcare practitioners in a tertiary care teaching hospital. ${ }^{15}$ Our findings also indicated that half of the participating physicians did not know if confidentiality should be protected after the patient's death. Meanwhile, in the study of Beltran et al, almost all of the participants answered that death does not overrule the physician's ethical obligation to protect the patient's confidentiality. ${ }^{12}$ Furthermore, in a study conducted in the Family Medicine Teaching Units (FMUs) at McGill University, staff members, including physicians, were asked if the police or third parties had the right to access medical files freely. Among the participating staff members, $72 \%$ correctly answered that police have restricted access, and 93\% correctly answered that without patient consent, non-healthcare personnel are denied access to medical files. ${ }^{16}$ Meanwhile, in our study, only $50.2 \%$ of the participants answered correctly with regards to police access and $56.1 \%$ with regards to the right of third parties to access patients' medical files. Similar to the physicians in our study, the physicians in the study of Beltran et al in Spain correctly agreed that patient confidentiality could be breached in cases of contagious diseases. ${ }^{11}$

Essential knowledge for identifying ethical problems in different patient care settings is based on ethics education. ${ }^{19}$ Therefore, advances in modern medicine included introducing medical ethics education in medical school curricula. ${ }^{19}$ In our study, most physicians reported having acquired their knowledge about data sharing during undergraduate study, and a similar percentage of the participants $(23 \%)$ reported having acquired their knowledge from experience and residency programs, suggesting better undergraduate ethics education for physicians. However, in the study of Hariharan et al, more than $70 \%$ of the participants reported having gained their knowledge about data sharing from their work experience. ${ }^{15}$ Despite this, and in congruence with our findings, most of the physicians in the study of Hariharan et al agreed that 
Table 4 Physician's Responses Related to Attitudes Towards Patient Confidentiality and Data Sharing

\begin{tabular}{|c|c|c|c|c|}
\hline & Never & Rarely & Sometimes & Always \\
\hline & $\mathbf{N}(\%)$ & $\mathbf{N}(\%)$ & $\mathbf{N}(\%)$ & $\mathbf{N}(\%)$ \\
\hline $\begin{array}{l}\text { I. I make sure to take the information from the patient and document it completely } \\
\text { confidentially }\end{array}$ & $0(0.0)$ & $4(1.8)$ & $48(21.7)$ & $169(76.5)$ \\
\hline 2. I discuss a patient's conditions with them in front of other patients to save time and place & $87(39.4)$ & $73(33.0)$ & $45(20.4)$ & $16(7.2)$ \\
\hline $\begin{array}{l}\text { 3. I allow non-medical personnel (eg, cleaning staff) to enter the examination room whilst } \\
\text { I am providing care to patients }\end{array}$ & $151(68.3)$ & $31(14.0)$ & $32(14.5)$ & $7(3.2)$ \\
\hline 4. I use a universal serial bus (USB) to store patient information & $153(69.2)$ & $30(13.6)$ & $25(11.3)$ & $13(5.9)$ \\
\hline 5. I use a personal computer to store patient information & $148(67.0)$ & $35(15.8)$ & $22(10.0)$ & $16(7.2)$ \\
\hline 6. I send patient information online & $142(64.3)$ & $42(19.0)$ & $27(\mid 2.2)$ & $10(4.5)$ \\
\hline 7. I send information by phone & $96(43.4)$ & $58(26.2)$ & $60(27.1)$ & $7(3.2)$ \\
\hline $\begin{array}{l}\text { 8. I deal with the information of patients with sensitive diseases (mental illnesses, sexual } \\
\text { diseases, etc.) with more caution }\end{array}$ & $19(8.6)$ & $16(7.2)$ & $37(16.7)$ & $149(67.4)$ \\
\hline $\begin{array}{l}\text { 9. I use virus protection and encryption software on the devices on which I store patient } \\
\text { information }\end{array}$ & $84(38.0)$ & $35(15.8)$ & $37(16.7)$ & $65(29.4)$ \\
\hline 10. I discuss my patients' conditions with my colleagues during work breaks & $15(6.8)$ & $50(22.6)$ & $124(56.1)$ & $32(14.5)$ \\
\hline $\begin{array}{l}\text { II. I discuss my patients' conditions with my colleagues in open spaces, such as reception } \\
\text { areas and corridors }\end{array}$ & III (50.2) & $69(31.2)$ & $29(13.1)$ & $12(5.4)$ \\
\hline 12. I discuss my patients' conditions with my friends outside the workplace & $90(40.7)$ & $62(28.1)$ & $58(26.2)$ & II (5.0) \\
\hline 13. I leave notes about my patients' conditions on my desk & $133(60.2)$ & $53(24.0)$ & $29(13.1)$ & $6(2.7)$ \\
\hline 14. I make and receive phone calls about patients' conditions when I am near other patients & $124(56.1)$ & $55(24.9)$ & $36(16.3)$ & $6(2.7)$ \\
\hline
\end{tabular}

Table 5 Predictors of Physicians' Knowledge About Patient Confidentiality and Data Sharing

\begin{tabular}{|c|c|c|c|c|c|}
\hline \multirow[t]{2}{*}{ Model } & \multicolumn{2}{|c|}{ Unstandardized Coefficients } & \multirow{2}{*}{$\begin{array}{l}\text { Standardized Coefficients } \\
\text { Beta }\end{array}$} & \multirow[t]{2}{*}{$\mathbf{t}$} & \multirow[t]{2}{*}{ Sig. } \\
\hline & B & Std. Error & & & \\
\hline (Constant) & $|2.69|$ & 2.216 & & 5.727 & 0.000 \\
\hline Specialty & 0.168 & 0.100 & 0.111 & 1.675 & 0.096 \\
\hline Sex & $1.47 \mathrm{I}$ & 0.501 & 0.200 & 2.933 & 0.004 \\
\hline Years of experience & -0.028 & 0.042 & -0.077 & -0.660 & 0.510 \\
\hline Age & 0.000 & 0.041 & -0.001 & -0.007 & 0.995 \\
\hline Marriage & -1.198 & 0.516 & -0.177 & -2.322 & 0.021 \\
\hline Number of treated patients/days & -0.058 & 0.148 & -0.026 & -0.393 & 0.695 \\
\hline Working setting & 0.010 & 0.127 & 0.006 & 0.080 & 0.936 \\
\hline Number of ethical dilemmas faced & 0.105 & 0.199 & 0.035 & 0.526 & 0.599 \\
\hline Preference in consulting on ethical dilemma & -0.248 & 0.105 & -0.155 & -2.351 & 0.020 \\
\hline Interest in taking medical ethics course & 0.103 & 0.735 & 0.009 & 0.141 & 0.888 \\
\hline
\end{tabular}


Table 6 Predictors of Physicians' Attitudes Toward Patient Confidentiality and Data Sharing

\begin{tabular}{|c|c|c|c|c|c|}
\hline \multirow[t]{2}{*}{ Model } & \multicolumn{2}{|c|}{ Unstandardized Coefficients } & \multirow{2}{*}{$\begin{array}{l}\text { Standardized Coefficients } \\
\text { Beta }\end{array}$} & \multirow[t]{2}{*}{$\mathbf{t}$} & \multirow[t]{2}{*}{ Sig. } \\
\hline & B & Std. Error & & & \\
\hline (Constant) & 29.009 & 4.027 & & 7.203 & 0.000 \\
\hline Specialty & -0.083 & 0.183 & -0.028 & -0.454 & 0.650 \\
\hline Sex & -2.797 & 0.911 & -0.199 & -3.070 & 0.002 \\
\hline Years of experience & 0.279 & 0.077 & 0.399 & 3.634 & 0.000 \\
\hline Age & -0.087 & 0.074 & -0.136 & -1.166 & 0.245 \\
\hline Marriage & -1.633 & 0.938 & -0.126 & $-1.74 \mid$ & 0.083 \\
\hline Number of treated patients/day & 0.277 & 0.269 & 0.065 & 1.028 & 0.305 \\
\hline Working setting & 0.127 & 0.230 & 0.036 & 0.551 & 0.583 \\
\hline Frequency of ethical dilemmas faced & 1.695 & 0.362 & 0.298 & 4.684 & 0.000 \\
\hline Preference in consulting on ethical dilemma & 0.057 & 0.191 & 0.019 & 0.297 & 0.767 \\
\hline Knowledge & 0.894 & 1.335 & 0.042 & 0.670 & 0.504 \\
\hline
\end{tabular}

further training on confidentiality laws is required. ${ }^{15}$ This raises concerns regarding whether physicians are provided with adequate ethics education after they graduate and engage in clinical practice.

In the present study, the factors that were found to predict knowledge scores were sex $(P=0.004)$, marriage ( $P=0.021)$, and the preference in consulting on the ethical dilemma $(P=0.020)$. Similarly, sex was found to predict knowledge in a study conducted in the United States (US) $(P=0.01) .{ }^{17}$ Furthermore, Beltran-Aroca et al reported that men outperformed women in knowledge about confidentiality. ${ }^{11}$ This differences between sex may be related to the sharing information between men and easiness of reaching access of information and advance of technology. ${ }^{24}$ Noticeably, age, experience, and specialty were not associated with knowledge among our sample. This is consistent with the findings of the aforementioned US study, whereby the number of years of experience, specialty, and level of training were not found to correlate with knowledge. ${ }^{17}$ Similarly, the multiple regression analysis that conducted by Abuhammad et $\mathrm{al}^{24}$ to comprehend the effect of the demographic attributes of nurses on data sharing and confidentiality of their patients, indicated that there was some connection between these attributes and the nurses on data sharing and confidentiality of their patients. These factors include age, gender, marriage status, and attending a security course before practice. Young age, female, not attending a data sharing course, and single nurses are less engaging with data sharing and confidentiality of the patients for unauthorized people.

Our study's physicians believed patient confidentiality to be particularly essential when dealing with patients with psychiatric or sexual diseases or patients taking illegal drugs. However, lack of sufficient knowledge may impact physicians' attitudes towards implementing patient confidentiality practices in different clinical settings. ${ }^{20}$ The mean score for attitudes towards confidentiality and data protection among the physicians in our study is similar to the low scores reported in Beltran et al study. ${ }^{11}$ Several studies have reported ethical misconduct among residents in different clinical settings. ${ }^{6,20,21}$ Mlinek et al, for instance, observed and recorded 26 sharing patients data with unauthorized people out of the 32 patients who existed in an emergency department (ED) waiting area in a university hospital in about 6 hours of observation. ${ }^{5}$ Moreover, 3-24 breaches per hour were recorded in the patient care area. ${ }^{5}$ Another study recorded breaches in 16 hospital departments for over more than 700 days, with around one breach occurring every 62.5 hours and $46.7 \%$ of the breaches being severe and $9.5 \%$ being repeated. ${ }^{6}$ Furthermore, similar to our findings, two previous studies reported that physicians primarily consult their colleagues when faced with an ethical dilemma. ${ }^{11,18}$ This suggests that patient privacy may be compromised by physicians consulting other physicians who are not involved in the patient's care. ${ }^{11}$ Interestingly, less than $10 \%$ of the 
participants in our study reported that they consulted their department's head or ethical committee when faced with ethical problems. Hariharan et al suggested that this may explain why junior practitioners face more problems than their consultant counterparts, as juniors may not report such problems to their seniors in the first place. ${ }^{15}$ This form of violation, which includes revealing patients' personal and medical data to third parties, was the most commonly reported form in Beltran et al study. ${ }^{15}$ Moreover, an observational study noted that $37.9 \%$ of sharing patients data with unauthorized people occurred in public areas, with over half of the observed incidents being related to consultations with uninvolved personnel. ${ }^{6}$

Likewise, discussing patient information outside the workplace is considered a confidentiality breach in communal areas. ${ }^{11}$ This includes patients in rooms closer to the nursing or/physicians' station, waiting areas in emergency departments, and/or elevators. ${ }^{7}$ Reassuringly, around two-thirds of the physicians in our study reported that they would never or rarely conduct such practice. Also, only $7 \%$ of the participating physicians reported that they would discuss patient information in front of other patients to save time. These practices, however, may be simply habitual rather than intentional, as suggested in several studies. ${ }^{20,22}$ However, our results indicated no correlation between the number of patients seen per day and physicians' attitudes towards data sharing and patient confidentiality. One previous study also attributed sharing patients data with unauthorized people to building design and floor planning. ${ }^{5}$ As expected, our results indicated that physicians with more years of experience and those who encountered more ethical dilemmas were more likely to adhere to practices that protected their patients' confidentiality.

The protection of patient confidentiality in daily medical practice includes the handling, communication, and management of a large amount of identifiable medical data. ${ }^{11}$ Only $17 \%$ of the physicians in our study reported that they stored patient data on their private computers, and more than $40 \%$ reported using virus protection and encryption software on the devices they used to store patient information. Other studies have suggested other practices that may lead to confidential data being leaked, including the failure to anonymize patient data and data storage on unprotected spaces, such as personal e-mails, personal laptops, and USB flash drives. ${ }^{23}$ A recent study reported the use of USB flash drives by 274 nurses $(34.3 \%)$ and e-mail by 127 nurses $(21 \%)$ for the storage of patient data. ${ }^{24}$ Meanwhile, only $17 \%$ of the physicians in our study reported that they always or sometimes used a USB flash drive or online spaces to store patient data.

\section{Implication of the Study}

The study findings showed that may be it is important when amending regulations and guidelines imposed by Jordan health authorities and other countries experiencing the same situation of confidentiality. Furthermore, it is also important to consider and develop a concise strategy to ensure the confidentiality, safety, and security of patient information while planning for the development and implementation of computerized systems and case management processes. Training is essential for all the physicians and health care providers who is working with patients since it will have a beneficial relationship with knowledge, opinions, views, and actions. Thus, planning continuous training on policies and regulations about data safety and privacy may assist in improving healthcare settings' practices.

\section{Limitation}

This study is a cross-sectional study that provides no evidence regarding the causes of our sample's observed knowledge and attitudes levels. Furthermore, two-thirds of the participants were men $(67.9 \%)$. However, this is considered to be representative of the sex ratio in the healthcare sector in Jordan. ${ }^{25}$ Besides, the participants' reporting of how frequently they faced ethical dilemmas may have been impacted by their limited awareness of what constitutes an ethical dilemma. Another limitation is response bias, which does not reflect the actual knowledge and attitude in the clinical area.

\section{Conclusion}

This study provides insight into physicians' knowledge and practices related to confidentiality. Despite being well aware of the importance of protecting patient confidentiality, the participating physicians were found to commit frequent sharing patients data with unauthorized people in their medical practice. Moreover, the participants were found to have inadequate levels of knowledge about correct data sharing practices, suggesting that they did not fully understand their obligations towards patient confidentiality. Future studies that investigate the factors that contribute to ethical misconduct and the impact of continued ethics education on physicians' knowledge and practice are recommended.

\section{Data Sharing Statement}

The datasets generated and analyzed during the current study are available with the corresponding author. 


\section{Compliance with Ethical Standards}

All procedures performed in this study involving human participants were reviewed and ethically approved by the Institutional Review Board (IRB) and the research and ethics committee at Jordan University of Science and Technology. This study was conducted following the 1975 Helsinki declaration, as revised in 2008 and its later amendments or comparable ethical standards.

\section{Informed Consent}

Informed consent was obtained from all individual participants included in the study.

\section{Funding}

Work on this project was supported by grant number 5R25TW010026-02 from the Fogarty International Center of the US National Institutes of Health. The funders had no role in the study design; collection, analysis, and interpretation of data; writing of the report; or the decision to submit for publication.

\section{Disclosure}

The authors declare that they have no competing interests.

\section{References}

1. Weiner BA, Wettstein RM. Confidentiality of patient-related information. Arch Ophthalmol. 1994;112(8):1032-1036. doi:10.1001/ archopht.1994.01090200038018

2. Dodek DY, Dodek A. From Hippocrates to facsimile. Protecting patient confidentiality is more difficult and more important than ever before. CMAJ. 1997;156(6):847-852.

3. O'Brien J, Chantler C. Confidentiality and the duties of care. J Med Ethics. 2012;109(8):36LP- 40. doi:10.1136/jme.29.1.36

4. Entwistle VA, Carter SM, Cribb A, McCaffery K. Supporting patient autonomy: the importance of clinician-patient relationships. $J$ Gen Intern Med. 2010;25(7):741-745. doi:10.1007/s11606-010-1292-2

5. Mlinek EJ, Pierce J. Confidentiality and privacy breaches in a university hospital emergency department. Acad Emerg Med. 1997;4(12):1142-1146. doi:10.1111/j.1553-2712.1997.tb03697.x

6. Beltran-Aroca CM, Girela-Lopez E, Collazo-Chao E, Montero-PérezBarquero M, Muñoz-Villanueva MC. Sharing patients data with unauthorized people in clinical practice: what happens in hospitals? BMC Med Ethics. 2016;17(1):52. doi:10.1186/s12910-016-0136-y

7. Ubel PA, Zell MM, Miller DJ, Fischer GS, Peters-Stefani D, Arnold RM. Elevator talk: observational study of inappropriate comments in a public space. Am J Med. 1995;99(2):190-194. doi:10.1016/ S0002-9343(99)80139-9
8. Baldwin DCJ, Daugherty SR, Rowley BD. Unethical and unprofessional conduct observed by residents during their first year of training. Acad Med. 1998;73(11):1195-1200. doi:10.1097/ 00001888-199811000-00019

9. Lehrer JA, Pantell R, Tebb K, Shafer M-A. Forgone health care among U.S. adolescents: associations between risk characteristics and confidentiality concern. $J$ Adolesc Heal. 2007;40(3):218-226. doi:10.1016/j.jadohealth.2006.09.015

10. Noroozi M, Zahedi L, Bathaei FS, Salari P. Challenges of confidentiality in clinical settings: compilation of an ethical guideline. Iran J Public Health. 2018;47(6):875-883.

11. Beltran-Aroca CM, Labella F, Font-Ugalde P, Girela-Lopez E. Assessment of doctors' knowledge and attitudes towards confidentiality in hospital care. Sci Eng Ethics. 2019;25(5):1531-1548. doi:10.1007/s11948-018-0078-5

12. Act DP. Data protection act. London Station Off; May, 1998.

13. Regulation P. General data protection regulation. Intouch; 2018:25.

14. Spencer A, Patel S. Applying the data protection act 2018 and general data protection regulation principles in healthcare settings. Nurs Manage. 2019;26(1):34-40. doi:10.7748/nm.2019.e1806

15. Hariharan S, Jonnalagadda R, Walrond E, Moseley H. Knowledge, attitudes and practice of healthcare ethics and law among doctors and nurses in Barbados. BMC Med Ethics. 2006;7(1):E7. doi:10.1186/ 1472-6939-7-7

16. Mohamed AM, Ghanem MA, Kassem AA. Knowledge, perceptions and practices towards medical ethics among physician residents of University of Alexandria hospitals, Egypt/ Connaissances, perceptions et pratiques en matiere d'ethique medicale des internes des centres hospitaliers universitaires d'Alexandrie (Egypte). East Mediterr Health J. 2012;18(9):935.

17. Wandrowski J, Schuster T, Strube W, Steger F. Medical ethical knowledge and moral attitudes among physicians in Bavaria. Dtsch Arztebl Int. 2012;109(8):141. doi:10.3238/arztebl.2012.0141

18. Beauchamp TL, Childress FJ. Principles of Medical Ethics. 7th ed. Oxford Univ Press; 2009.

19. Hafferty FW, Franks R. The hidden curriculum, ethics teaching, and the structure of medical education. Acad Med. 1994;69(11):861-871. doi:10.1097/00001888-199411000-00001

20. Elger BS. Violations of medical confidentiality: opinions of primary care physicians. Br J Gen Pract J R Coll Gen Pract. 2009;59(567): e34452. doi:10.3399/bjgp09X472647

21. Green MJ, Farber NJ, Ubel PA, et al. Lying to each other: when internal medicine residents use deception with their colleagues. Arch Intern Med. 2000;160(15):2317-2323. doi:10.1001/ archinte.160.15.2317

22. Dapaah JM, Senah KA. HIV/AIDS clients, privacy and confidentiality; The case of two health centres in the Ashanti Region of Ghana. BMC Med Ethics. 1994;17(1). doi:10.1186/s12910-016-0123-3

23. Karasneh RA, Al-Azzam SI, Alzoubi KH, Hawamdeh SS, Muflih SM. Patient data sharing and confidentiality practices of researchers in Jordan. Risk Manag Healthc Policy. 2019;25:1531-1548. doi:10.2147/RMHP.S227759

24. Abuhammad S, Alzoubi KH, Al-Azzam SI, Karasneh RA. Knowledge and practice of patients' data sharing and confidentiality among nurses in Jordan. J Multidiscip Healthc. 2020.

25. Jordan in figures 2018. Department of Statistics [Internet]; 2018. Available from: http://dosweb.dos.gov.jo/products/jordan-infigure2018/.Accessed February 23, 2021 


\section{Publish your work in this journal}

The International Journal of General Medicine is an international, peer-reviewed open-access journal that focuses on general and internal medicine, pathogenesis, epidemiology, diagnosis, monitoring and treatment protocols. The journal is characterized by the rapid reporting of reviews, original research and clinical studies across all disease areas. The manuscript management system is completely online and includes a very quick and fair peer-review system, which is all easy to use. Visit http://www.dovepress.com/ testimonials.php to read real quotes from published authors.

Submit your manuscript here: https://www.dovepress.com/international-journal-of-general-medicine-journal 